http://dx.doi.org/10.1590/0102-4698126337

\title{
TRAC̣OS E CONFIGURAC̣̃̃ES DO DISCURSO DA VULNERABILIDADE SOCIAL NO BRASIL - MODOS DE SER E GERENCIAR UMA PARCELA DA POPULAÇÃO
}

Rose Méri Santos da Silva"

Méri Rosane Santos da Silva**

RESUMO: Este artigo tem como objetivo problematizar o processo de constituição dos discursos que nomeiam e constituem determinadas crianças e/ou adolescentes no Brasil como vulneráveis sociais. Utilizou-se de uma fundamentação teórica pautada nas formulações de Michel Foucault, assim como se assumiu, enquanto investimento metodológico, operar com algumas ferramentas da genealogia foucaultiana. Adotou-se como corpus de análise as constituições brasileiras, documentos infraconstitucionais e as legislações relacionados ao campo da Assistência Social. Dessa maneira, buscou-se compreender a trajetória de produção do discurso da vulnerabilidade social, enfatizando a própria constituição da referida terminologia, que foi percorrendo caminhos que vão desde o vínculo com a questão do direito internacional, penetrando na área da saúde e da temática da Aids/HIV, até adentrar as vias das condições socioeconômicas. Enfim, ao identificar, categorizar e atribuir uma nomeação de vulnerabilidade social a determinados indivíduos produzem-se esses sujeitos e uma população a ser conhecida, controlada, gerida e gerenciada.

Palavras-Chave: Vulnerabilidade social. Crianças e/ou adolescentes. Genealogia.

\footnotetext{
* Doutora em Educação em Ciências: Química da Vida e Saúde da Universidade Federal do Rio Grande (FURG). Professora da Escola Superior de Educação Física da Universidade Federal de Pelotas (UFPel). Membro do Grupo de Pesquisa Observatório das Práticas Corporais e Políticas da Vida. E-mail: roseufpel@yahoo.com.br * Doutora em Ciências do Movimento Humano pela Universidade Federal do Rio Grande do Sul (UFRGS). Professora do Instituto de Educação da Universidade Federal do Rio Grande (FURG) e do Programa de PósGraduação em Ciências: Química da Vida e Saúde. Líder do Grupo de Pesquisa Observatório das Práticas Corporais e Políticas da Vida. E-mail: meri.rosane@hotmail.com
} 


\title{
SETTINGS OF THE SOCIAL VULNERABILITY SPEECH IN BRAZIL: WAYS OF BEING AND MANAGING A SHARE OF THE POPULATION
}

\begin{abstract}
This article aims at problematizing the process of producing speeches that point and constitute as social vulnerable certain part of child and teenagers' population in Brazil. Theoretical grounding was based on Michel Foucault's formulations, as well as some of Foucault's genealogy tools were assumed here as a methodological investment. We adopted as an analysis corpus the Brazilian constitution, infra-constitutional documents, and legislation related to Social Assistance. Thus, it was sought to understand the trajectory of the social vulnerability speech with highlights to the process of the referred terminology constitution itself. Starting point is related to its link to international rights issues, entering the thematic of health AIDS/HIV, until ingoing the paths of socioeconomic conditions. Finally by identifying, categorizing, and attributing social vulnerability tag to certain individuals, one produces these subjects who constitute a population to be known, controlled, operated, and managed.
\end{abstract}

Keywords: Social vulnerability. Children and/or teenagers. Genealogy.

\section{APRESENTAÇÃO}

O presente artigo foi elaborado com o objetivo de problematizar o processo de constituição dos discursos que se referem às crianças e/ou aos adolescentes nomeados atualmente no Brasil como vulneráveis sociais, considerando-o como um acontecimento ${ }^{1}$ que possui "seu lugar e consiste na relação, coexistência, dispersão, recorte, acumulação, seleção de elementos materiais" (FOUCAULT, 1970 , p. 57) e deve ser compreendido dentro de uma moldura que se move, se desloca, a partir das condições de possibilidades que operam, assim como dos efeitos produzidos.

Faz-se necessário destacar que se aciona aqui a noção de problematizar não no sentido de desconstruir algo ou mesmo de questionar se uma instância é verdadeira ou falsa, certa ou errada, válida ou inválida. Estamos nos referindo, isso sim, a diagnosticar " $\mathrm{O}$ conjunto das práticas discursivas ou não discursivas que faz alguma coisa entrar no jogo do verdadeiro e do falso e o constitui como objeto para o pensamento" (FOUCAULT, 1984, p. 242).

Utilizou-se, como norteador para essa produção textual, de uma fundamentação teórica pautada nas formulações de Michel Foucault, assim como é também a partir do referido autor que se assumiu, enquanto investimento metodológico, operar com algumas ferramentas da genealogia. 
Torna-se relevante destacar que não é de um uso qualquer da genealogia que se está assumindo como potente para esse trabalho, mas, isso sim, em uma perspectiva utilizada por Michel Foucault, que foi buscar em Nietzsche atravessamentos que a tornaram um modo de operar seus estudos, como se pode observar na configuração de suas obras dedicadas a problematizar as práticas, os acontecimentos nas suas singularidades, assim como a produção dos sujeitos, as relações de poder e de saber que se constituem a partir de situações específicas, contextualizadas histórica e socialmente.

É essa utilização da genealogia, colocada em movimento por Foucault ao longo de seus trabalhos, que serviu de inspiração metodológica para buscar compreender o processo de constituição do discurso da vulnerabilidade social, que se faz presente em diversas instâncias do nosso cotidiano e, mais especificamente, em instituições como os núcleos denominados de Atendimento Socioeducativo em Meio Aberto (ASEMA) de Pelotas.

Faz-se necessário salientar que ASEMA (Atendimento Socioeducativo em Meio Aberto) é uma política de atendimento instituída pelo Estatuto da Criança e do Adolescente - ECA (Lei 8.069/90), destinado à proteção de crianças e adolescentes em vulnerabilidade social. Especificamente, o trabalho aqui apresentado remete-seaos ASEMA de Pelotas (RS), locais esses, sob responsabilidade da Secretaria Municipal de Direitos Humanos, Cidadania e Assistência Social (SMDHCAS), distribuídos em regiões periféricas da cidade e nos quais atuei como técnica em Educação Física.

É dentro desse cenário que a presente produção textual se compõe, adotando inicialmente como corpus de análise ${ }^{3}$ as constituições brasileiras, posteriormente, imergindo nas documentações infraconstitucionais, até chegar às legislações relacionados com o campo da Assistência Social, que receberam um destaque especial, pois foi neles, que surgiu pela primeira vez uma legislação fazendo uso da terminologia vulnerabilidade social.

\section{OPERANDO UMA POSSIBILIDADE DE PROCEDIMENTO GENEALÓGICO}

No campo teórico em que o presente trabalho se construiu, estabelecer um caminho único torna-se um empreendimento disperso, difuso ou mesmo sem consistência, pois as realidades e as verdades vão se constituindo e se imbricando de uma maneira tal que se forma uma espécie de caleidoscópio ${ }^{4}$ gigante, em que a 
imagem a ser formada se transforma a cada mexida das peças, não se podendo jamais determinar qual seria a primeira, nem mesmo ter a pretensão de que as possibilidades de formação de novas imagens estejam esgotadas. Sendo assim, o que nos propomos, ao operar com um procedimento genealógico, foi problematizar as condições e as possibilidades que foram se engendrando e atuando na composição do discurso da vulnerabilidade social, a partir do olhar que fomos lançando sobre os documentos em referência.

Saliente-se que, ao proceder dessa maneira, se trabalhou com uma linearidade histórica que se manifestou somente no sentido de uma organização de apresentação do referido trabalho. Não nos atrelamos ao sentido tradicional da história, que supõe uma verdade como eterna, um ponto de partida (origem), que perpassa por todo o tempo, como se fosse a procura de uma

essência exata da coisa, sua mais pura possibilidade, sua identidade cuidadosamente recolhida em si mesma, sua forma imóvel e anterior a tudo o que é externo, acidental, sucessivo. (...) Procurar por tal origem é tentar reencontrar 'o que era imediatamente', 'o aquilo mesmo' de uma imagem exatamente adequada a si (...); é querer tirar todas as máscaras para desvelar enfim uma identidade primeira. (FOUCAULT, 1988, p. 17)

O tratamento que atribuímos à história é sob um ponto de vista genealógico, ou seja, nele o sentido histórico reconhece que vivemos sem referências, que não temos coordenadas originárias, que vivemos em miríades de acontecimentos perdidos.

A história dos historiadores constrói um ponto de apoio fora do tempo; ela pretende tudo julgar segundo uma objetividade apocalíptica; (...) Em compensação, o sentido histórico escapará da metafísica para tornar-se um instrumento privilegiado da genealogia se ele não se apóia sobre nenhum absoluto. Ele deve ter apenas a acuidade de um olhar que distingue, reparte, dispersa, deixa operar as separações e as margens - uma espécie de olhar que dissocia e é capaz ele mesmo de se dissociar e apagar a unidade deste ser humano que supostamente o dirige soberanamente para seu passado. (FOUCAULT, 1993, p. 29)

Dentro dessa perspectiva, para a efetivação do presente empreendimento, é preciso conhecer as condições de formação dos acontecimentos, é uma tentativa de compreender como eles se constituem, como se apresentam na sua singularidade. Não se trata de reescrever o passado em termos do presente, aceitando como dadas as categorias de análises estabelecidas, é preciso, isto sim, restituir o jogo das interações que existem entre saberes e poderes específicos.

De este modo se trata de hacer entrar en interacción las relaciones que existen 
en el ámbito microfísico com las de alcance más general, por lo que es preciso conferir en el análisis una especial importancia a lás mediaciones. Y es que son precisamente los procesos mediadores, y correlativamente la necesidad de emplear conceptos elaborados para dar cuenta de procesos situados a distinto nivel, quienes obligan a un trabajo de innovación. (VARELA; ALVARES-URIA, s/d, p. 7)

Foucault, citado por Deleuze (1988, p. 58), espera da história uma noção muito própria, que "é esta determinação dos visíveis e dos enunciáveis em cada época", ou seja, a maneira de dizer e a forma de ver, em cada época, que ultrapassa os comportamentos e as mentalidades, as ideias, tornando-as possíveis. Ainda, segundo Deleuze, a "História só responde porque Foucault soube inventar, sintonizando com as novas concepções dos historiadores, uma maneira propriamente filosófica de interrogar, maneira nova e que dá nova vida à História" (DELEUZE, 1988, p. 59).

\subsection{ADENTRANDO A MASSA DOCUMENTAL}

Ao movimentar o corpus de análise, destacou-se, inicialmente, a Constituição de 1824, considerada a de maior vigência, pois durou mais de 65 anos. Nesse período o país vivia em um Estado centralizado, com uma monarquia hereditária e constitucional. $\mathrm{Na}$ referida constituição não havia referência a uma parcela específica de brasileiros que fizesse distinção entre adultos e crianças, sendo todos tratados como cidadãos, como pode se verificar, por exemplo, no art. 179, do Título $8^{\circ}$ - Das Disposições Geraes, e Garantias dos Direitos Civis, e Politicos dos Cidadãos Brazileiros ${ }^{5}$

Art. 179. A inviolabilidade dos Direitos Civis, e Politicos dos Cidadãos Brazileiros, que tem por base a liberdade, a segurança individual, e a propriedade, é garantida pela Constituição do Imperio, pela maneira seguinte.

I. Nenhum Cidadão póde ser obrigado a fazer, ou deixar de fazer alguma cousa, senão em virtude da Lei.

Esse fato repete-se também na Constituição de 1891, pois nela não se encontra ainda nenhuma especificação que se refira às crianças e/ou aos adolescentes, tratando toda a população brasileira como igual e detentora dos mesmos direitos, como se pode averiguar no Título IV - Dos Cidadãos Brasileiros, na Seção I - Das Qualidades do Cidadão Brasileiro em seu Art. 69. 
Art 69 - São cidadãos brasileiros:

$1^{\circ}$ ) os nascidos no Brasil, ainda que de pai estrangeiro, não, residindo este a serviço de sua nação;

$2^{\circ}$ ) os filhos de pai brasileiro e os ilegítimos de mãe brasileira, nascidos em país estrangeiro, se estabelecerem domicílio na República;

$3^{\circ}$ ) os filhos de pai brasileiro, que estiver em outro país ao serviço da República, embora nela não venham domiciliar-se;

$4^{\circ}$ ) os estrangeiros, que achando-se no Brasil aos 15 de novembro de 1889 , não declararem, dentro em seis meses depois de entrar em vigor a Constituição, o ânimo de conservar a nacionalidade de origem;

$5^{\circ}$ ) os estrangeiros que possuírem bens imóveis no Brasil e forem casados com brasileiros ou tiverem filhos brasileiros contanto que residam no Brasil, salvo se manifestarem a intenção de não mudar de nacionalidade; $6^{\circ}$ ) os estrangeiros por outro modo naturalizado

Somente a partir da Constituição de 1934 é que ocorrerá uma referência específica em relação à infância e à juventude, como se pode verificar no Título IV - Da Ordem Econômica e Social, em seu Art. 138, que incumbe à União, aos Estados e aos Municípios: assegurar amparo aos desvalidos, criando serviços especializados e animando os serviços sociais, cuja orientação procurara coordenar; amparar a maternidade e a infância; proteger a juventude contra toda exploração.

Desse modo, as categorias da infância e da juventude são legalmente inventadas, ou seja, esses grupos saem do anonimato e passam a existir, sendo considerados a partir de então, segundo critérios baseados em um mundo próprio, diferente do adulto.

Temos, assim, que essa divisão da vida humana em etapas distintas é uma invenção social, historicamente construída, e não algo naturalmente concebido. Especificamente em relação à questão da infância, Bujes apresenta-a como algo que passou a fazer parte da história recentemente, ou mesmo como "um acontecimento caracteristicamente moderno, produto de uma série de condições que se conjugam e que estabelecem novas possibilidades de compreensão de um fenômeno que antes de uma realidade biológica, como se quis fazer crer, é um fato cultural por excelência" (2000, p. 26).

Nesse sentido, Ariès (1981, p. 18) trabalha com a noção de que o reconhecimento da infância como uma fase da existência do ser humano não existia, ou seja, "partimos de um mundo de representação onde a infância é desconhecida", ela é tida como um "período de transição, logo ultrapassado, e cuja lembrança também era logo perdida". O referido autor coloca ainda que essa categoria 
da vida humana não existia porque suas particularidades, que as distinguia do mundo adulto, não eram consideradas, como pode ser verificado no trecho a seguir descrito:

Na Idade Média, no início dos tempos modernos, e por muito tempo ainda nas
classes populares, as crianças misturavam-se com os adultos assim que eram
consideradas capazes de dispensar a ajuda das mães ou das amas, poucos anos
depois de um desmame tardio - ou seja, aproximadamente, aos sete anos de idade.
A partir desse momento, ingressavam imediatamente na grande comunidade dos
homens, participando com seus amigos jovens ou velhos dos trabalhos e dos
jogos de todos os dias. (ARIĖS, 1981, p.193)

Além da invenção da infância, temos que considerar, também, que, nessa época, o país vivia sob a égide de um capitalismo emergente, e o embate pela consolidação das leis trabalhistas se fazia muito presente. Foi nesse período que ocorreu a criação da Justiça do Trabalho e foram implementadas leis que instituíram a jornada de trabalho de oito horas, o repouso semanal e as férias remuneradas.

Vê-se que as principais referências que essa legislação dispensa a essa nova categoria, que é a infância e a juventude, são no sentido de torná-las produtivas e adequá-las ao mercado de trabalho, como podemos verificar no Art. 121, que se destina a promover "o amparo da produção e estabelecerá as condições do trabalho, na cidade e nos campos, tendo em vista a proteção social do trabalhador e os interesses econômicos do País”. Para isso, o referido artigo atribui que a legislação do trabalho observará, dentre os seus preceitos, a

$\mathrm{Na}$ Constituição de 1937, os detalhamentos dos cuidados dispensados à infância e à juventude vão se especificando cada vez mais. Tais fatos podem ser verificados na seção destinada à Família, em seu Art. 127, quando diz que a

Proibição de trabalho a menores de 14 anos; de trabalho noturno a menores de 16 e em indústrias insalubres, a menores de 18 anos e a mulheres.

Tal constituição também institui, no mesmo artigo, que o abandono moral, intelectual ou físico da infância e da juventude será considerado como

Infância e a juventude devem ser objeto de cuidados e garantias especiais por parte do Estado, que tomará todas as medidas destinadas a assegurar-lhes condições físicas e morais de vida sã e de harmonioso desenvolvimento das suas faculdades. 
Outro diferencial que surge a partir desse documento é a questão da institucionalização, ou seja, a colocação de crianças e/ ou adolescentes aos cuidados de um estabelecimento especializado, como estratégia de proteção da infância e da juventude, assim como a atribuição dessa responsabilidade ao Estado, como se pode observar na parte que se refere à Educação e à Cultura, no Art. 129, que atribui à

Falta grave dos responsáveis por sua guarda e educação, e cria ao Estado o dever de provê-las do conforto e dos cuidados indispensáveis à preservação física e moral.

Nesse período vivia-se em um regime conhecido como Estado Novo, que foi marcado por um golpe militar, protagonizado pelo então presidente da República Getúlio Vargas, caracterizando uma época conhecida como Era Vargas. Nessa fase, os partidos políticos foram abolidos, passando a adotar um Governo com características ditatoriais e desempenhando um papel bastante intervencionista, inclusive na economia.

Essas intervenções estatais visavam regulamentar as condições de trabalho dessa parcela da população, nomeada de infância e juventude, buscando assim potencializá-las e torná-las produtivas, como podemos verificar no artigo abaixo descrito, que se refere à seção da Ordem Econômica:

Art. 137 - A legislação do trabalho observará, além de outros, os seguintes preceitos:

(...) k) proibição de trabalho a menores de catorze anos; de trabalho noturno a menores de dezesseis, e, em indústrias insalubres, a menores de dezoito anos e a mulheres.

Nas próximas constituições, tanto na de 1946 como na de 1967, não ocorre nenhuma modificação quanto à maneira de se referir às crianças e/ou aos adolescentes, sendo que somente com a promulgação da Constituição Federal de 1988, denominada Constituição Cidadã, é que se observará uma mudança quanto à nomenclatura que passa a adotar a expressão "crianças e adolescentes carentes", como podemos verificar em sua Seção III - da Assistência Social, em seu Art. 203, que prevê "O amparo às crianças e adolescentes carentes".

Ao analisar essa pequena massa documental, composta pelas constituições que regulamentaram o país, observou-se que 
não existe nenhuma citação ao termo vulnerabilidade social, sendo que as referências que se fazem presentes, em relação à nomeação de crianças e/ou adolescentes, quando passaram a existir, se estabeleceram de uma maneira bastante generalizante e mais na perspectiva de torná-las produtivas, sejam no sentido de produção nos moldes capitalistas, ou mesmo na perspectiva de evitar qualquer desestabilização do contexto social vivido.

O processo seguinte foi observar as documentações infraconstitucionais, ou seja, aqueles dispositivos e leis que implementam as constituições, tentando explicitar a maneira como os discursos ali presentes nomeavam essa parcela da população, composta de crianças e/ou adolescentes, como em situação de vulnerabilidade social.

Inicialmente destacou-se o Código de Menores (Decreto 17947/27), considerado como o primeiro documento legal voltado ao atendimento da população menor de 18 anos, editado, no Brasil, em 1927. Popularmente chamado de Código Mello de Mattos ${ }^{6}$, essa lei passou a vigorar frente a uma grande efervescência social no país. O presidente era Washington Luiz, que administrava uma nação em meio à carestia, à recessão e a um aumento da população urbana, principalmente de menores de 19 anos, que, naquele momento, representavam 51\% da população (ARAÚJO; COUTINHO, 2007).

Nesse documento, a terminologia utilizada para caracterizar essas crianças e/ou adolescentes era a de "menores abandonados" . Vê-se aqui identificados discursos marcando e objetivando uma determinada parcela da população como "menores abandonados", ou seja, não era todo e qualquer menor assim classificado, mas somente aqueles que apresentassem as características indicadas pelo Código de Menores (alínea I, II, V e VII), que podiam ser relacionadas desde à situação de mendicância, pobreza ou mesmo à falta de residência fixa. Salienta-se, ainda, que o referido documento nomeava como abandonados não somente aqueles que fossem submetidos a situações desfavoráveis, mas também a todos que desempenhassem comportamentos ou atitudes tidas como anormais para os padrões da época (alínea V e VI).

Outro fator a ser enfatizado é a forma de aproximar, categorizar, padronizar e associar a questão da pobreza com os desvios de condutas. Assim, menores abandonados seriam aqueles que não atingissem as condições mínimas de sobrevivência, os pobres, mas também todos que rompessem com os padrões de normalidade comportamentais e morais. 
O caráter da pobreza infantil, considerada como a falta de acesso aos bens de consumo e de sobrevivência, vai sendo vinculado com a questão da criminalidade e da violência. Essa situação pode ser observada desde o período de formação da população brasileira, pois nessa época era muito presente a prática do abandono de crianças, que pode ter como uma das causas o fato apontado por Marcílio (2006, p. 103), ou seja,

a população brasileira, em toda a sua história, não pôde reproduzir inteiramente
o modelo da família ideal, criado no Ocidente cristão e trazido ao Brasil pela
Igreja e pelos colonizadores portugueses. Devido a razões complexas - e que
vêm sendo estudadas pelos demógrafos historiadores nas últimas décadas -
uma grande parcela da nossa população foi fruto de relacionamentos mantidos
fora do quadro da família sacramentada. Somente na cidade de São Paulo,
entre 1750 e $1850,25 \%$ das crianças nascidas livres provinham de casais
concubinatos, e $15 \%$ tinham sido abandonadas ao nascer. Com certeza, uma
boa parte desta era também de ilegítimos.

Essas crianças eram enviadas a instituições como as Casas de Misericórdias, que apresentavam altos índices de mortalidade infantil ${ }^{8}$ e aqueles que sobreviviam eram enviados precocemente ao mercado de trabalho. As crianças, principalmente as do sexo masculino, atuariam como aprendizes nas Companhias de Marinheiros ou nas Companhias de Arsenal de Guerra, sendo que nesses locais conviviam com presos comuns, portugueses degredados e escravos condenados às galés ${ }^{9}$, numa brusca inserção no mundo do trabalho e no mundo da violência (MARCÍLIO, 2006, p. 185).

Ainda segundo a referida autora, durante meados do século XVII e início do século XVIII, o abandono de crianças passou a ser uma prática socialmente condenada, principalmente porque os maus cuidados e a indiferença com relação à infância faziam com que grande parte delas morresse. Para ela, quando isso representou um risco para o Estado, já que não haveria mão de obra para a indústria nem força para o Exército, em um país que se encontrava em franco desenvolvimento industrial, é que o abandono passou a ser tomado como um problema social, demográfico e político, resultando inclusive no fechamento das instituições a que essas crianças abandonadas eram enviadas.

Já em 1979, teremos a implementação da Lei 6697/79, que altera o Código de Menores e introduz o conceito de "menor em situação irregular", como podemos ver em seu Art. $1^{\circ}$, do Livro I, na Parte Geral, no Título I - Disposições Preliminares, ao afirmar que este código "dispõe sobre assistência, proteção e vigilância a menores: até 18 anos de idade, que se encontrem em situação irregular". 
Mesmo com a mudança de nomenclatura, de menores abandonados para menores em situação irregular, vê-se que os aspectos anteriormente citados permanecem vigorando, ou seja, mantêm-se uma objetivação de determinado grupo de menores e/ou adolescentes, assim como o imbricamento entre a noção de pobreza, questões comportamentais e de violência.

Afora os documentos relacionados às constituições e aos regulamentos infraconstitucionais, os dispositivos e as leis que se referem à regulamentação do trabalho são outra grande fonte, encontradas no sentido de caracterizar esses sujeitos que hoje se constituem como vulneráveis sociais. Isso pode ser verificado no Art. 402 da Consolidação das Leis de Trabalho, datada de 1967, no Título III, das Normas Especiais de Tutela do Trabalho, que traz no Capítulo IV, Seção I, nas Disposições Gerais:

Considera-se menor para os efeitos desta Consolidação o trabalhador de quatorze até dezoito anos.

Parágrafo único - O trabalho do menor reger-se-á pelas disposições do presente Capítulo, exceto no serviço em oficinas em que trabalhem exclusivamente pessoas da família do menor e esteja este sob a direção do pai, mãe ou tutor, observado, entretanto, o disposto nos arts. 404, 405 e na Seção II.

Nos documentos relacionados ao campo da Assistência Social também foi possível identificar outras indicações legais que se referiram a nomear crianças e/ou adolescentes como em vulnerabilidade social.

A Assistência Social é uma área de conhecimento que foi se consolidando no Brasil a partir de 1937, quando se registra duas ações: a criação do Conselho Nacional de Serviço Social (CNSS); e, na década de 40, com a implementação da Legião Brasileira de Assistência. Nesse período, o país estava passando por um processo de redemocratização, pois, em 1945, o então presidente Getúlio Vargas é deposto e, em 1946, é promulgada uma nova Constituição, de caráter liberal, mas que, como apontado anteriormente, ainda mantinha a lógica de somente referir-se a essa parcela da população, caracterizada como crianças e/ou adolescentes, ao tratar da regulamentação das condições de trabalho.

Em 1977 é criado o Ministério da Previdência e Assistência Social, mas somente em 1988, através da promulgação da Constituição, é que se reconhece a Assistência Social como dever de Estado no campo da seguridade social e não mais como uma política isolada e complementar à Previdência. 
Posteriormente a Loas (Lei Orgânica da Assistência Social), Lei Federal 8.742, de 07 de dezembro de 1993, definiu algumas alterações institucionais, visando à organização da Assistência Social no Brasil, estabelecendo como objetivo da Assistência Social o amparo às crianças carentes e atribuindo a competência de cada um dos órgãos responsáveis pela execução dos projetos de enfrentamento da pobreza. Percebe-se, assim, um fortalecimento da área, pois seu campo de atuação amplia-se para os setores da família, da maternidade, da infância, da adolescência e da velhice, criando em todos eles a necessidade de ser atendidos.

De todas as mudanças que se efetivaram no campo da Assistência Social, nesse período no Brasil, destaca-se como relevante, para esse trabalho, o texto final da Política Nacional da Assistência Social (PNAS) e a Norma Operacional Básica do Suas ${ }^{10}$ (NOB/Suas), datados de setembro de 2004 e de março de 2005 respectivamente, e que trazem, no item referente aos objetivos da proteção social básica, a expressão vulnerabilidade social, como podemos verificar no excerto abaixo:

A proteção social básica tem como objetivos prevenir situações de risco através do desenvolvimento de potencialidades e aquisições, e o fortalecimento de vínculos familiares e comunitários. Destina-se à população que vive em situação de vulnerabilidade social (...) (PNAS, 2004, p.19) (NOB/SUAS, 2005, p. 20).

Tais documentações expressam oficialmente pela primeira vez a terminologia vulnerabilidade social, que mesmo não estando presente em nenhuma constituição brasileira, passa a fazer parte do cotidiano da população, assim como a ser recorrente em diversas legislações, principalmente após a década de 80 , absorvendo-a da área da saúde, quando foi amplamente utilizada com relação ao HIV/Aids.

\subsection{A VULNERABILIDADE SOCIAL EM FOCO}

Para que esse processo de constituição do vocábulo "vulnerabilidade" e, mais especificamente da expressão vulnerabilidade social, seja compreendido, faz-se necessário problematizar o sentido dos diversos elementos utilizados, pois um vocábulo não pode ser reduzido simplesmente à expressão de uma ideia, ele é temporal, circunstancial, pode remeter a significações e ações diferentes, portanto, entende-se que, nesse referencial teórico, torna-se imprescindível ressaltar o significado das palavras. 
No que se refere à vulnerabilidade, ela é tomada como a "qualidade de vulnerável", sendo que o termo passou a significar a suscetibilidade "de ser ferido ou atacado; diz-se do ponto por onde uma pessoa pode ser atacada ou ferida" (CARVALHO; PEIXOTO, 1972, p. 1054). Partindo dessa abordagem inicial, vamos perscrutar um pouco das andanças, ao longo do tempo, para tentar compreender os caminhos percorridos pelo referido tema, até assumir a dimensão e os sentidos utilizados em nossos dias.

Em princípio, sua utilização está atrelada à área da advocacia internacional, como podemos observar na obra Os Direitos Humanos como Tema Global, de Lindgren Alves, quando se refere a "grupos ou indivíduos fragilizados, jurídica ou politicamente, na promoção, proteção ou garantia de seus direitos de cidadania" (AYRES et al., 2003, p. 118). Saliente-se que a referida obra foi elaborada sobre forte influência do final da Guerra Fria e pelo crescente processo de democratização de todo o mundo, sendo que nessa época os direitos humanos e todas as temáticas a eles relacionadas eram centrais nas discussões internacionais.

Posteriormente, vamos assistir a uma potencialização, bastante significativa, no emprego do conceito de vulnerabilidade, ao estabelecer seu vínculo com as análises na área da saúde e, mais especificamente, das pesquisas sobre o HIV/Aids. Ayres et al. (2003, p. 118) ressalta que "o conceito de vulnerabilidade, especificamente aplicado à saúde, pode ser considerado o resultado do processo de progressivas interseções entre o ativismo diante da epidemia da Aids e o movimento dos Direitos Humanos".

Nesse cenário, ele passa a ser adotado nos discursos voltados para as temáticas da saúde pública, principalmente às formas de prevenção da referida doença, assim como das questões de intervenção junto às pessoas, aos grupos e às populações. Dessa forma, a expressão vulnerabilidade consolida-se como sendo

o resultante de um conjunto de aspectos não apenas individuais, mas também coletivos, contextuais, que acarretam maior suscetibilidade à infecção e ao adoecimento e, de modo inseparável, maior ou menor disponibilidade de recursos de todas as ordens para se proteger de ambos (AYRES et al., 2003, p. 123).

Somente a partir do fim da década de 90 é que encontramos referências à questão da vulnerabilidade social, mas ainda relacionada a questões da saúde, vinculando-se à Aids e às chances de exposição das pessoas ao adoecimento. Porém, nesse período, os discursos relacionados à referida temática ampliam sua abrangência, envolvendo 
outros setores. A partir desse aumento de amplitude é que a vulnerabilidade social passa a ser considerada uma das três dimensões que, segundo Sanches (1999, p. 108), a referida expressão pode assumir, juntamente com a individual e a programática.

Sanches (1999, p.110) aponta que a dimensão individual é aquela que considera todos os comportamentos que criam oportunidades para que as pessoas venham a contrair doenças ou a viver em determinadas condições desfavoráveis, assim como quanto ao grau de consciência que essas pessoas e grupos têm sobre tais comportamentos e, ainda, quanto ao efetivo poder que podem exercer para transformá-los. Já o componente programático da vulnerabilidade envolve o grau e a qualidade de compromisso, recursos, gerência e monitoramento de programas nacionais, regionais ou locais de prevenção, que são importantes para identificar as necessidades, direcionar os recursos sociais existentes e potencializar seu uso. Por último, a dimensão social é considerada aquela que envolve o acesso às informações, às possibilidades de compreendê-las e ao poder de incorporá-las a mudanças práticas na vida cotidiana.

O conceito de vulnerabilidade social desloca-se de uma perspectiva analítica, referindo-se somente a indicadores quantitativos de um campo específico, seja ele do direito ou mesmo da saúde, para adentrar em uma concepção mais ampla, complexa e multifacetada, ou seja, em uma perspectiva sintética, em que são considerados também os diversos aspectos que influenciam nas condições de vulnerabilidade de uma pessoa ou grupo, tais como as possibilidades de acesso à estrutura de oportunidades sociais, econômicas, culturais que proveem do Estado, do mercado e da sociedade.

Como efeitos gerados por esse deslocamento da abrangência do campo de atuação das temáticas da vulnerabilidade, se passam a agregar outras áreas de saberes como o da educação, da assistência social, da psicologia, assim como se observa outro aspecto a ser destacado - a aproximação da temática da vulnerabilidade social com uma reflexão voltada às condições socioeconômicas, passando, assim, a serem assumidas pelas políticas públicas adotadas pelo Estado. Nessa perspectiva, o conceito de vulnerabilidade social passa a ser tomado como

o resultado negativo da relação entre a disponibilidade dos recursos materiais ou simbólicos dos atores, sejam eles indivíduos ou grupos, e o acesso à estrutura de oportunidades sociais, econômicas, culturais que provêm do Estado, do mercado e da sociedade (ABRAMOVAY, 2002, p. 13). 
Isso pode ser verificado também na definição do Suas (Sistema Único de Assistência Social), que atribui o conceito de vulnerabilidade social àqueles indivíduos que vivem em situação de pobreza ou privação (ausência de renda, precário ou nulo acesso aos serviços públicos, dentre outros) ou mesmo que tenham fragilização de vínculos afetivos relacionais e de pertencimento social - discriminação etária, étnicas, de gênero ou por deficiência, dentre outras (Suas - Resolução 130/2005).

Filgueira e Peri (2004, p. 08-10) apontam ainda algumas considerações interessantes ao definir o referido termo como sendo "la escasa capacidad de respuesta individual o grupal ante riesgos y contingencia.(...) Por extensión, se puede afirmar que es también una predisposición negativa para la superación de condiciones adversas". Ainda, segundo o mesmo autor, nessa perspectiva, vulnerabilidade social pode ser definida como "una configuración particular, negativa, resultante de la intersección de dos conjuntos; uno, definido a nivel 'macro' relativo a la estructura de oportunidades y otro definido a nivel 'micro', referido a los activos de los actores" (FILGUEIRA; PERI, 2004, p. 21).

Vemos surgir outro aspecto de grande relevância nessa discussão, que é o envolvimento da noção de risco com a temática da vulnerabilidade. Segundo Spink (2003, p. 150), a palavra "risco" passa a ser utilizada a partir do século XIV, sendo que somente no século XVI é que adquire seu sentido moderno, constituindo-se como um "híbrido entre perigo e controle". Ressalte-se, ainda, que "a noção de risco que é própria da modernidade está intimamente relacionada à incorporação cultural da noção de probabilidade" (SPINK, 2003, p. 151). Segundo Traversini (2003, p. 111),

a invenção do risco possibilitou classificar espaços e indivíduos, ou um conjunto deles, com determinadas características (...) como problemáticos, necessitando serem administrados de determinado modo para evitar sua multiplicação e a geração de elevadas despesas para o Estado.

Mas esses múltiplos discursos relacionados às questões do risco e da vulnerabilidade social estão imersos em um cenário bastante turvo, sombrio e imbricado, ou seja, as margens demarcatórias dos campos de abrangência entre vulnerabilidade e risco são muito ínfimas, delicadas, ou mesmo não definidas, tornando-as muitas vezes confundíveis. Não são poucas as vezes em que nos deparamos com suas utilizações sendo feitas como sinonímias, outras com meras aproximações não muito claras, ou mesmo atribuindo-lhes sentidos opostos, antagônicos. É um pouco disso que passaremos a tratar a 
partir de agora, mas esclareço que não tenho a intenção de enquadrálas como certas ou erradas, ou mesmo de estabelecer um juízo de valor, uma como melhor que a outra, mas o que pretendemos é problematizar alguns aspectos considerados aqui como relevantes.

Traversini (2003, p. 110) nos traz uma análise sobre a questão de risco como algo já existente, mesmo antes da Modernidade, mas vinculado a aspectos naturais (chuva, temporais etc.), sobrenaturais (fantasmas, bruxas etc.) e reais (bandidos, saqueadores etc.), estando presentes muitas estratégias para "evitar os males e vigiar os perigos que poderiam se abater sobre as pessoas". A referida autora enfatiza, ainda, que a produção de insegurança não estava relacionada com a responsabilidade humana, mas com a vontade da natureza e do próprio sobrenatural.

A ampliação dos usos da noção de risco envolve diversas áreas de conhecimento, mas é no campo da saúde que sua utilização é bastante potencializada, principalmente vinculada aos aspectos dos riscos de contaminação relacionados ao vírus do HIV/Aids. Esse panorama se estabeleceu, mais fortemente, na década de 80 , dando ênfase à questão dos mecanismos causais ${ }^{11}$ a comportamentos individuais para, em um segundo momento, a partir do final desta década até nossos dias, passarem a coexistir também os enfoques que levavam em conta as características mais contextuais e estruturais, mas ainda remetendo-se às formas de cuidado e prevenção referentes ao indivíduo.

Faz-se necessário aqui enfatizar uma distinção, um afastamento, não uma oposição, entre essas duas dimensões, risco e vulnerabilidade, ou seja, as práticas de prevenção referentes aos riscos eram destinadas basicamente ao comportamento específico dos indivíduos, passando posteriormente a considerar também as relações e interações estruturais em que ocorrem os riscos de contaminação. É nesse momento de mudança e ampliação da magnitude da referida temática é que a expressão "vulnerabilidade" se fortalece, pois apresenta uma maior amplitude conceitual, sendo colocada na ordem não somente no cuidado do indivíduo, mas também dos outros, das populações.

Ayres et al. (2003, p. 127) apontam que a diferença entre esses dois conceitos é o caráter iminentemente analítico do risco, em contraste com as aspirações sintéticas da vulnerabilidade. Percebese, então, que a produção de conhecimento, elaborada a partir da noção de risco, era baseada em instrumentos capazes de isolar, de determinar, quase matematicamente, os processos de adoecimento 
especificamente relacionados à conduta de um indivíduo, seja na ordem de um disciplinamento de ações individuais ou mesmo na determinação da probabilidade de ocorrência dos comportamentos.

Já as questões da vulnerabilidade nascem de uma pretensão diferente, pois os saberes e as verdades produzidas sobre ela são fundamentados na ênfase de situações que expressem as possibilidades de ocorrência e no controle dos fatos relacionados a todos os envolvidos, ou seja, ela atua como um dispositivo de segurança que age por meio do gerenciamento das probabilidades de ocorrência das questões de cada indivíduo, mas considerando-os parte integrante de uma população. Segundo Abramovay (2002, p. 22),

a objetivação da vulnerabilidade social desloca-se do campo da AIDS e da saúde exclusivamente e amplia-se para a esfera da vida social, juntando-se aos campos da educação, do trabalho, das políticas públicas em geral, na medida em que se refere às condições de vida e suportes sociais, e não à conduta, como marcava o conceito de risco.

A partir da noção de risco, associada ao conceito de vulnerabilidade, as práticas de intervenções, utilizadas pelos programas de saúde pública, também modificaram seu foco, passando a atuar mais em torno dos grupos com comportamentos tidos como de riscos, considerando todas as possibilidades que interferem nos mecanismos de causalidade, ou seja, em todos os fatores estruturais que podem causar o risco de contaminação. Dessa forma, a expressão vulnerabilidade vai se legitimando, como podemos observar com a caracterização apontada por Sanches (1999, p. 110), para o qual

\footnotetext{
este conceito aponta para um conjunto de fatores, de níveis e magnitudes distintos, cuja interação amplia ou reduz as possibilidades de uma pessoa se infectar com o HIV. Nessa perspectiva, os comportamentos individuais de maior ou menor exposição ao risco são considerados em relação a um conjunto mais amplo de determinantes, que devem ser contemplados no planejamento das intervenções preventivas.
}

Pode-se verificar que esses dois universos - vulnerabilidade e risco social - não são excludentes, eles interagem, coexistem, se imbricam e se complementam no sentido de nomear e gerenciar uma determinada camada da população, que passa a ter uma visibilidade, a ser conhecida e reconhecida. Assim, os discursos relacionados à vulnerabilidade social operam como estratégias de saber e de poder que atuam a partir da probabilidade de ocorrência das situações de risco, mas sempre no sentido de um controle, de uma segurança da população envolvida. 


\section{CONCLUSÕES POSSIVEIS}

Ao finalizar este trabalho evoca-se novamente a figura do caleidoscópio, para tornar presente o princípio de não esgotamento de possibilidades, com a ideia de busca por outras imagens, de viajar por outros horizontes, procurando vislumbrar outros caminhos que não se esgotam nem mesmo se completam.

É nesse sentido que o referido artigo foi elaborado demonstrando um procedimento genealógico para atingir o objetivo central dessa produção textual, que é abordar a noção de vulnerabilidade social operada em políticas sociais para crianças e adolescentes.

Ao trabalharcom algumas ferramentas da genealogia foi possível esboçar uma trajetória da produção do discurso da vulnerabilidade social, percorrendo caminhos que vão desde o vínculo com a questão do direito internacional, penetrando na área da saúde e da temática da Aids/HIV, até adentrar as vias das condições socioeconômicas.

Mas torna-se importante destacar que esses discursos veiculados no sentido de caracterizar determinada parcela da população como em vulnerabilidade social são construções, ou seja, elas não são um fenômeno social atemporal ou mesmo "a-histórico", mas, isso sim, elas devem ser entendidas como o resultado de toda uma trajetória de construção histórica e cultural estabelecida.

Percebe-se, assim, que esses múltiplos discursos, assim como outras maneiras de nomear crianças e/ou adolescentes, tais como "santa infância, órfãos, infância desvalida, infância abandonada, petizes, peraltas, menores viciosos, infância em perigo moral, pobrezinhos sacrificados, vadios, capoeiras" (MARCILIO, 2006, p. 195), não presentes em documentos constitucionais, mas utilizados ao trabalhar com a mudança da designação da infância, mantêm como ponto em comum a questão do risco, assim como a necessidade de controle e gerenciamento tanto dos indivíduos como das populações em que estão inseridos.

Ao identificar, nomear, categorizar, atribuir uma qualidade a determinados indivíduos produz-se esses sujeitos, que passam a integrar uma população a ser controlada, conduzida, corrigida.

Pode-se verificar, então, que de ações dirigidas a sujeitos vulneráveis produz-se a vulnerabilização dos mesmos, ou seja, são indivíduos que passam a existir a partir das características que lhes são atribuídas, compondo assim uma população a ser gerida, gerenciada, buscando atingir o equilíbrio ou mesmo uma espécie de homeostase da vida. 


\section{REFERÊNCIAS}

ABRAMOVAY, M. et al. Juventude, violência e vulnerabilidade social na América Latina: desafios para políticas públicas. Brasília: UNESCO, 2002.

AYRES J. R. C. de M. et al. In: CZERESNIA, D. (org.) Promoção da saúde: conceitos, reflexões, tendências. Rio de Janeiro: Fiocruz, 2003.

ARAÚJO, D. C.; COUTINHO, I. S. S. 80 anos do Código de Menores. Mello Mattos: a vida que se fez lei. FADIPA - Faculdade de Direito de Patos de Minas. Disponível em: < http:// www.portalfadipa.com.br/br/cartilhacidada.php>. Acesso em: 22 maio 2008.

ARIÈS, P. História social da criança e da família. 2. ed. Rio de Janeiro: Copyright, 1981.

CARVALHO, J.; PEIXOTO, V. Dicionário da língua portuguesa. 20. Ed. São Paulo: Cultural Brasil, 1972.

CASTRO, E. Vocabulário de Foucault - um percurso pelos seus temas, conceito e autores. Belo Horizonte: Autêntica Editora, 2009.

DELEUZE, G. Foucault. 1. ed. São Paulo: Brasiliense, 1988.

FISCHER, R. M. B. A paixão de trabalhar com Foucault. In: COSTA, M. V. (org.). In: Caminhos investigativos: novos olhares na pesquisa em educação. 2. ed. Rio de Janeiro: DP\&A, 2007.

FILGUEIRA, C.; PERI, A. América Latina: los rostros de la pobreza y sus causas determinantes. Santiago: Copyright, 2004.

FOUCAULT, M. 1984. O cuidado com a verdade. In: Ditos e Escritos $V$ - Ética, sexualidade, política. Tradução de Elisa Monteiro, Inês Autran Dourado Barbosa; [org. Manoel Barros da Motta] - Rio de Janeiro: Forense Universitária, 2006.

Microfísica do poder. Organização e tradução de Roberto Machado. 11. ed. Rio de Janeiro: Edições Graal, 1993.

História da sexualidade I: a vontade de saber. Tradução de Maria Thereza da Costa Albuquerque e J. A. Guilhon Albuquerque. 13. ed. Rio de Janeiro: Edições Graal, 1988.

A ordem do discurso. Aula inaugural no Collège de France, pronunciada em 2 de dezembro de 1970. Tradução de Laura Fraga de Almeida Sampaio. 13. ed. São Paulo: Loyola, 2006.

MARCÍLIO, M. L. História social da criança abandonada. 2. ed. São Paulo: HUCITEC, 2006.

MICHAELIS. Minidicionário escolar da língua portuguesa. São Paulo: Companhia Melhoramentos, 2000.

RESOLUÇÃO CNAS no 130/2005, Norma Operacional do Suas. Disponível em: < http:// www.mds.gov.br>. Acesso em: 15 dez. 2006.

SANCHES, K. R. de B. A AIDS e as mulheres jovens: uma questão de vulnerabilidade, 1999. Disponível em: <http://portalteses.cict.fiocruz.br/transf.php>. Acesso em: 24 fev. 2007.

SPINK, M. J. Estudo sobre tecnobiociências na sociedade. 2003. Disponível em: < http://www.ensp. fiocruz.br/projetos/esterisco/suor2.htm>. Acesso em: 22 jul. 2008.

TRAVERSINI, C. S. Programa alfabetização solidaria, o governamento de todos e de cada um. Porto Alegre, Tese (dout.) Faced/PPGEDU/UFRGS.

VARELLA, J.; ALVAREZ-URIA, F. ElMetodo Genealogico. Madrid: Universidad Complutense, mimeo, s/d.

\section{NOTAS}

${ }^{1}$ Acontecimento é tratado aqui como "cesuras que rompem o instante e dispersam o sujeito em uma pluralidade de posições e de funções possíveis" (FOUCAULT, 1970, p. 58). 
${ }^{2}$ Proponho-me a utilizar a concepção de diagnosticar no sentido de "estabelecer o que constitui nosso presente, os acontecimentos que repetimos [...]. Não se trata de compreender o presente a partir do passado (como uma época do mundo) nem do futuro (como anúncio ou promessa), mas em sua diferença, a partir de si mesmo" (CASTRO, 2009, p. 107).

${ }^{3}$ Aqui corpus de análise deverá ser entendido como "um conjunto de textos associados a inúmeras práticas sociais", considerando-se ainda que "esses textos não seriam realidades mudas, as quais, por um trabalho de interpretação e análise, seriam despertas, revelando sentidos escondidos, palavras talvez nunca faladas, as quais seriam orientadas por uma certa iluminação teórica definidora do que realmente diriam os ditos". Eles serão vistos e entendidos na "sua materialidade pura e simples de coisas ditas em determinado tempo e lugar” (FISCHER, 2007, p. 43).

${ }^{4}$ Caleidoscópio é um aparelho óptico formado por um tubo de cartão ou de metal, com pequenos fragmentos de vidro colorido que se refletem em pequenos espelhos inclinados, apresentando, a cada movimento, combinações variadas (MICHAELIS, 2000, p.110).

${ }^{5}$ Todos os excertos evidenciados do corpus de análise serão destacados em uma caixa de texto conforme apresentado a seguir.

${ }^{6}$ José Cândido de Albuquerque Mello Mattos foi jurista, escritor e advogado. Considerado o primeiro Juiz de Menores da América Latina e foi referenciado pelas discussões internacionais em torno do tema. Promoveu a consolidação e a sistematização de uma legislação de assistência e proteção aos menores.

${ }^{7}$ Como se pode verificar, por exemplo, no Art. 26 do capítulo IV da referida lei.

${ }^{8}$ Nessas instituições, as taxas de mortalidade infantil eram elevadíssimas, as mais altas de todos os segmentos da sociedade, inclusive dos escravos. Eram encontradas cifras de $85 \% \mathrm{e}$ mesmo de 90\% de mortes antes do primeiro ano de vida (MARCÍLIO, 2006, p. 105).

${ }^{9}$ Galés são espécies de antigas embarcações de guerra, compridas e estreitas, que emergiam pouco acima da água, impelidas basicamente por grandes remos (CARVALHO; PEIXOTO, 1971, p. 512).

${ }^{10} \mathrm{O}$ Suas é um sistema constituído por um conjunto de serviços, programas, projetos e benefícios no âmbito da assistência social, prestados diretamente - ou através de convênios com organizações sem fins lucrativos - por órgãos e instituições públicas federais, estaduais e municipais da administração direta e indireta e das fundações mantidas pelo poder público.

${ }^{11}$ Utilizou-se aqui a expressão "mecanismos causais" em um sentido mais biológico, que atribui uma relação direta entre as condições de causa-efeito das doenças, ou seja, refere-se à ideia de que o desenvolvimento de uma enfermidade poderia ser atribuído a uma causa determinada e específica.

Recebido: 10/11/2013

Aprovado: 14/08/2014

Contato:

Rua Casemiro de Abreu, 361 Areal

Pelotas $\mid$ RS | Brasil

CEP 96.077-040 